\title{
Molecular Subtyping of Blastocystis sp. Isolated from Farmed Animals in Southern Italy
}

\author{
Simona Gabrielli ${ }^{1,2}$ (1) , Marialetizia Palomba ${ }^{1}$, Federica Furzi ${ }^{1}$, Emanuele Brianti ${ }^{3}$, Gabriella Gaglio ${ }^{3}$, \\ Ettore Napoli ${ }^{3}$, Laura Rinaldi ${ }^{4}\left(\mathbb{D}\right.$, Renato Aco Alburqueque ${ }^{1}$ and Simonetta Mattiucci ${ }^{1,2, *}$ \\ 1 Department of Public Health and Infectious Diseases, Sapienza University of Rome, Piazzale Aldo Moro 5, \\ 00185 Rome, Italy; simona.gabrielli@uniroma1.it (S.G.); marialetizia.palomba@uniroma1.it (M.P.); \\ federica.furzi@uniroma1.it (F.F.); renatoacoalburqueque@gmail.com (R.A.A.) \\ 2 Diagnostic Parasitology Laboratory, Umberto I University Hospital, Viale del Policlinico 155, \\ 00185 Rome, Italy \\ 3 Department of Veterinary Sciences, University of Messina, Polo Universitario Annunziata, \\ 98168 Messina, Italy; ebrianti@unime.it (E.B.); ggaglio@unime.it (G.G.); enapoli@unime.it (E.N.) \\ 4 Department of Veterinary Medicine and Animal Production, University of Naples Federico II, \\ Via della Veterinaria 1, 80137 Naples, Italy; lrinaldi@unina.it \\ * Correspondence: simonetta.mattiucci@uniroma1.it; Tel.: +39-064-991-4894
}

\section{check for} updates

Citation: Gabrielli, S.; Palomba, M.; Furzi, F.; Brianti, E.; Gaglio, G.; Napoli, E.; Rinaldi, L.; Alburqueque, R.A.; Mattiucci, S. Molecular Subtyping of Blastocystis sp. Isolated from Farmed Animals in Southern Italy. Microorganisms 2021, 9, 1656. https://doi.org/10.3390/ microorganisms 9081656

Academic Editor: María Teresa Gómez-Muñoz

Received: 21 May 2021

Accepted: 31 July 2021

Published: 3 August 2021

Publisher's Note: MDPI stays neutral with regard to jurisdictional claims in published maps and institutional affiliations.

Copyright: (c) 2021 by the authors. Licensee MDPI, Basel, Switzerland. This article is an open access article distributed under the terms and conditions of the Creative Commons Attribution (CC BY) license (https:/ / creativecommons.org/licenses/by/ $4.0 /)$.

\begin{abstract}
Blastocystis is a common intestinal protist distributed worldwide, infecting humans and a wide range of domestic and wild animals. It exhibits an extensive genetic diversity and, so far, 25 distinct small subunit ribosomal RNA (SSU rRNA) lineages termed subtypes (STs)) have been characterized; among them, 12 have thus far been reported in humans. The aims of the present study were to detect and genetically characterize Blastocystis sp. in synantropic animals to improve our current knowledge on the distribution and zoonotic transmission of Blastocystis STs in Italy. Samples were collected from N=193 farmed animals and submitted to DNA extraction and PCR amplification of the SSU rRNA. Blastocystis was detected in 60 samples (31.08\%) and successfully subtyped. Phylogenetic analysis evidenced that the isolates from fallow deer, goats, and pigs $(N=9)$ clustered within the ST5; those from pheasants $(N=2)$ in the ST6; those from chickens $(N=8)$ in the ST7; those from sheep $(N=6)$ in the ST10; and those from water buffaloes $(N=9)$ in the ST14 clade. The comparison between the present isolates from animals and those previously detected in humans in Italy suggested the animal-to-human spillover for ST6 and ST7. The present study represents the widest Blastocystis survey performed thus far in farmed animals in Italy. Further epidemiological studies using molecular approaches are required to determine the occurrence and distribution of Blastocystis STs in other potential animal reservoirs in Italy and to define the pathways of zoonotic transmission.
\end{abstract}

Keywords: Blastocystis; subtypes; animals; Italy; molecular identification; phylogenetic analysis; zoonotic transmission

\section{Introduction}

Blastocystis is a common intestinal protist distributed worldwide, currently known as belonging to the Stramenopiles [1], infecting humans and a wide range of domestic and wild animals [2]. As the pathogenetic role is still controversial, there is not yet a consensus about the term to describe the host-protist interaction, which could be considered an "infection" or a "colonization" [3].

The life cycle of Blastocystis remains incompletely known thus far. However, experimental infectivity studies in animals have demonstrated that the water- and environmentalresistant infective cysts are the transmission stage $[4,5]$. Upon ingestion, excystment takes place in the host intestine, giving rise to vacuolar forms, which divide by binary fission and may develop further into amoeboid or granular forms. Later, encystment may occur during the passage down the colon before cyst excretion in the feces [6]. 
Molecular studies based on the small subunit ribosomal RNA (SSU rRNA) have so far allowed the identification in mammalian and avian hosts of possibly 25 distinct ribosomal lineages, termed subtypes (STs), which could be considered separate species $[7,8]$. Among the Blastocystis ribosomal lineages, 12 subtypes have thus far been identified in humans. In detail, STs 1-4 have been frequently found in humans, but they have also been detected in hoofed mammals, primates, pigs, cattle, rodents, and even birds [9]. Conversely, STs $5-8$ have been rarely reported in humans and more commonly found in animals. For instance, ST5 is typically detected in hoofed animals, ST6 and ST7 in birds, and ST8 in non-human primates [10].

Therefore, it has been proposed that a portion of human infection or colonization by Blastocystis may result from the zoonotic transmission of the protist. However, the contribution of animal sources to human infection/colonization remains to be confirmed, as the direction of the transmission route to humans is still uncertain [11].

In recent years, the presence of Blastocystis has also attracted attention in Italy, where few epidemiological surveys have been published so far, demonstrating the occurrence in humans of seven STs, including those considered as zoonotic (i.e., ST1, ST2, ST3, ST4, ST6, ST7, and ST8) [12-16].

In addition, the protist has been identified in fresh products [17] and in untreated drinking water [18], providing evidence of transmission thought contaminated food or water.

Despite that a prevalence rate of about $7 \%$ has been reported in the Italian population [15,19], along with the identification of zoonotic STs in humans [12-14], studies investigating the animal species harboring the protist in Italy and their potential role as a source of human infection/colonization still remain limited. So far, the detection of different STs from animals was carried out in few animal categories such as zoo mammals [20], dogs [21], imported macaques [22], and domestic and wild suids [23].

In this frame, the aims of the present study were to (i) detect and genetically characterize Blastocystis in synanthropic animals such as farmed animals and (ii) improve our current knowledge on the distribution of Blastocystis STs in animals in Italy and their possible transmission routes to humans.

\section{Materials and Methods}

\subsection{Sample Collection}

During the year 2018, fecal samples were randomly collected from animals sampled from different farms in two regions of Southern Italy, which were selected because of the simultaneous presence of different animal species including poultries and untreated with antibiotics in the previous months. In detail, three farms were located in the Messina province (Sicily region), while samples from water buffaloes were collected in nine and two farms from the Salerno and Caserta province (Campania region), respectively.

Samples were directly collected from rectal ampulla to avoid environmental contamination. Animals included in the study were apparently in a good state of health and did not report any clinical signs of concurrent infection by other pathogens.

\subsection{DNA Extraction and Sequencing of Blastocystis Isolates}

Genomic DNA was extracted from each fecal sample using the Fecal DNA kit (Bioline, Taunton, MA, USA) according to the manufacturer's protocol. A fragment of about $500 \mathrm{bp}$ from the SSU rRNA gene was amplified using the primers Blast 505-532 $\left(5^{\prime}\right.$ GGAGGTAGTGAC AATAAATC-3') and reverse Blast 998-1017 (5'-TGCTTTCGCACTTGTT CATC $\left.-3^{\prime}\right)$ following the protocol proposed by Santín et al. [24]. Positive samples were further amplified using the primers RD5 (5'-ATCTGGTTGATCCTGCCAGT-3') and BhRDr (5'-GAGCTTTTTAACTGCAACAACG-3'), in order to compare sequences obtained in this study with human isolates from our previous survey $[13,15]$, using the PCR-conditions described in Scicluna et al. [25]. PCR amplicons obtained with this PCR protocol were purified and Sanger sequenced from both strands with the same primers, at the Sequencing Service of Biofab Research through an Automated Capillary Electrophoresis Sequencer 
ABI3730 DNA Analyzer (Applied Biosystems, Carlsbad, CA, USA), using the BigDye ${ }^{\circledR}$ Terminator v3.1 Cycle Sequencing Kit (Life Technologies, Carlsbad, CA, USA).

The resulting chromatograms were analyzed and edited in the computer software Chromas version 2.33 (South Brisbane, Queensland, Australia). The sequences obtained were then compared to the sequences of Blastocystis STs, previously deposited in GenBank ${ }^{\mathrm{TM}}$ (https:/ / www.ncbi.nlm.nih.gov/genbank/, accessed on 1 February 2021) and PUBMLST databases (https:/ / pubmlst.org/organisms/blastocystis-spp, accessed on 1 February 2021). The subtypes (STs) were identified by determining the exact match $(100 \%)$ or closest identity (99\%), according to the classification of the subtypes given by Stensvold et al. [26].

All sequences were submitted to GenBank ${ }^{\mathrm{TM}}$, reported with their accession numbers MZ242080-MZ242085.

\subsection{Phylogenetic and Genetic Diversity Analyses}

Phylogenetic analysis, based on the obtained sequences at the SSU rRNA from those positive samples, was inferred from Bayesian inference (BI) using MrBayes, v. 3.2.7 [27]. The Bayesian posterior probability analysis was performed using the MCMC algorithm, with four chains, 0.2 as the temperature of heated chains, 5,000,000 generations, a subsampling frequency of 500, and a burn-in fraction of 0.25 . Posterior probabilities were estimated and used to assess the support for each branch. Values with a 0.90 posterior probability were considered well-supported. Homologous Blastocystis SSU rRNA gene nucleotide sequences, available in GenBank database (accessed on 1 February 2021), were included to generate the phylogenetic tree, rooted using Proteromonas lacertae a.n. U37106.1 as outgroup.

Genetic distances were computed using the Kimura 2-Parameters (K2P) model [28] with 1000 bootstrap re-samplings, by MEGA Software, version 7.0.

\section{Results}

A total of $N=193$ fecal samples were collected from farmed animals, i.e., water buffaloes $(N=101)$, cow $(N=13)$, donkey $(N=2)$, duck $(N=2)$, fallow deer $(N=1)$, goat $(N=9)$, chicken $(N=17)$, horse $(N=3)$, ostrich $(N=2)$, peacock $(N=7)$, pheasant $(N=11)$, pig $(N=13)$, sheep $(N=11)$, and turkey $(N=1)$. Out of 193 stool samples, $60(31.08 \%)$ were positive at Blastocystis by the molecular analysis. The number of positive samples varied among the animal host species, as detailed in Table 1.

Table 1. Molecular identification and subtyping of Blastocystis collected from various animal species.

\begin{tabular}{|c|c|c|c|c|c|}
\hline Host & Scientific Name & $\begin{array}{c}\text { Collected } \\
\text { Samples }(N)\end{array}$ & $\begin{array}{l}\text { Positive Samples } \\
(\%)\end{array}$ & STs Identified & Alleles \\
\hline Cow & Bos taurus & 13 & $1(7.69)$ & untypable & - \\
\hline Donkey & Equus asinus & 2 & 0 & - & - \\
\hline Duck & $\begin{array}{c}\text { Anas } \\
\text { platyrhynchos domesticus }\end{array}$ & 2 & 0 & - & - \\
\hline Fallow deer & Dama dama & 1 & $1(100)$ & 5 & 17 \\
\hline Goat & Capra aegagrus hircus & 9 & $4(44.4)$ & 5 & - \\
\hline Chicken & $\begin{array}{c}\text { Gallus gallus } \\
\text { domesticus }\end{array}$ & 17 & $8(47)$ & 7 & 41 \\
\hline Horse & Equus caballus & 3 & 0 & - & - \\
\hline Ostrich & Struthio camelus & 2 & 0 & - & - \\
\hline Peacock & Pavo sp. & 7 & $3(42.85)$ & untypable & - \\
\hline Pheasant & $\begin{array}{l}\text { Phasianus } \\
\text { colchicus }\end{array}$ & 11 & $6(54.5)$ & 6 & 122 \\
\hline Pig & $\begin{array}{l}\text { Sus scrofa } \\
\text { domesticus }\end{array}$ & 13 & $10(76.92)$ & 5 & $17,115,153$ \\
\hline Sheep & Ovis aries & 11 & $9(81.8)$ & 10 & 152 \\
\hline Turkey & $\begin{array}{l}\text { Meleagris } \\
\text { gallopavo }\end{array}$ & 1 & 0 & - & - \\
\hline Water buffalo & Bubalus bubalis & 101 & $18(17.82)$ & 14 & 157 \\
\hline Total & & 193 & $60(31.08 \%)$ & & \\
\hline
\end{tabular}


Among the positive samples, 34 were successfully sequenced, showing the presence of a single ST. The remaining 26 PCR products displayed unreadable sequences for the entire region (about $600 \mathrm{bp}$ ). Only sequences that showed chromatograms with single peaks were analyzed, while the subtype identification was not performed from chromatograms with double signals. Indeed, the presence of double signals in the chromatograms, which is very common in Blastocystis sequences from animals, may be indicative of mixed infections by different STs in the same host. In this case, the cloning of the PCR product or next generation amplicon sequencing would be required to discriminate such different subtypes [8]. In this study, the ST identification protocol followed the PCR amplification coupled with sequencing, which preferentially allowed to identify the predominant subtype.

Analysis of readable sequences showed a high identity (99-100\%) to homologous sequences of Blastocystis previously reported in GenBank ${ }^{\mathrm{TM}}$, allowing the BLAST identification of five distinct STs (i.e., ST5, ST6, ST7, ST10, and ST14) (Table 2). The topology of Bayesian inference (BI) showed that the Blastocystis isolates analyzed here clustered, with high probability value (from $99 \%$ to $100 \%$ ), in five distinct clades. In particular, the sequences of Blastocystis obtained from deer $(n=1)$, pig $(n=7)$, and goat $(n=1)$ clustered in the clade that includes the previously deposited sequences of the subtype ST5; those from pheasant $(n=2)$ and chicken $(n=8)$ were clustered in the clades formed by the available sequences of ST6 and ST7, respectively; and, finally, those from sheep $(n=6)$ and water buffalo $(n=9)$ were included with high probability value $(100 \%)$, respectively, in the clades formed by the reference sequences of the subtypes named ST10 and ST14 (Figure 1).

Table 2. BLAST correspondence of Blastocystis sequences obtained in the present study with those Blastocystis subtypes (STs) available in the GenBank ${ }^{\mathrm{TM}}$ database reported with their host, geographic origin, and accession number.

\begin{tabular}{|c|c|c|c|c|c|}
\hline Sample ID/Isolate & $\begin{array}{c}\text { Blastocystis Subtype } \\
\text { (GenBank Accession } \\
\text { Number) }\end{array}$ & Host & Locality & References & Similarity (\%) \\
\hline Phaesant91 & ST6 (MW713074) & Tibetan goat & China & $\begin{array}{l}\text { Chang et al., } \\
\text { unpublished }\end{array}$ & 99.63 \\
\hline Phaesant89 & ST6 (MW713074) & Tibetan goat & China & $\begin{array}{l}\text { Chang et al., } \\
\text { unpublished }\end{array}$ & 99 \\
\hline Chicken31 & ST7 (KY488585) & - & Southwest of Iran & $\begin{array}{l}\text { Salehi et al., } \\
\text { unpublished }\end{array}$ & 100 \\
\hline Chicken32 & ST7 (KY488585) & - & Southwest of Iran & $\begin{array}{l}\text { Salehi et al., } \\
\text { unpublished }\end{array}$ & 100 \\
\hline Chicken33 & ST7 (KY488585) & - & Southwest of Iran & $\begin{array}{l}\text { Salehi et al., } \\
\text { unpublished }\end{array}$ & 100 \\
\hline Chicken34 & ST7 (KY488585) & - & Southwest of Iran & $\begin{array}{l}\text { Salehi et al., } \\
\text { unpublished }\end{array}$ & 100 \\
\hline Chicken35 & ST7 (KY488585) & - & Southwest of Iran & $\begin{array}{l}\text { Salehi et al., } \\
\text { unpublished }\end{array}$ & 100 \\
\hline Chicken37 & ST7 (KY488585) & - & Southwest of Iran & $\begin{array}{l}\text { Salehi et al., } \\
\text { unpublished }\end{array}$ & 100 \\
\hline Chicken38 & ST7 (KY488585) & - & Southwest of Iran & $\begin{array}{l}\text { Salehi et al., } \\
\text { unpublished }\end{array}$ & 100 \\
\hline Chicken39 & ST7 (KY488585) & - & Southwest of Iran & $\begin{array}{l}\text { Salehi et al., } \\
\text { unpublished }\end{array}$ & 100 \\
\hline Sheep140 & ST10 (MF186708) & Wallaby & - & $\begin{array}{l}\text { Betts et al., } \\
\text { unpublished }\end{array}$ & 99.80 \\
\hline Sheep145 & ST10 (MF186708) & Wallaby & - & $\begin{array}{l}\text { Betts et al., } \\
\text { unpublished }\end{array}$ & 99.80 \\
\hline Sheep146 & ST10 (MF186708) & Wallaby & - & $\begin{array}{l}\text { Betts et al., } \\
\text { unpublished }\end{array}$ & 99.80 \\
\hline
\end{tabular}


Table 2. Conts.

\begin{tabular}{|c|c|c|c|c|c|}
\hline Sample ID/Isolate & $\begin{array}{c}\text { Blastocystis Subtype } \\
\text { (GenBank Accession } \\
\text { Number) }\end{array}$ & Host & Locality & References & Similarity $(\%)$ \\
\hline Sheep147 & ST10 (MF186708) & Wallaby & - & $\begin{array}{l}\text { Betts et al., } \\
\text { unpublished }\end{array}$ & 99.80 \\
\hline Sheep148 & ST10 (MF186708) & Wallaby & - & $\begin{array}{l}\text { Betts et al., } \\
\text { unpublished }\end{array}$ & 99.80 \\
\hline Sheep149 & ST10 (MF186708) & Wallaby & - & $\begin{array}{l}\text { Betts et al., } \\
\text { unpublished }\end{array}$ & 99.80 \\
\hline Buffalo10_2 & ST14 (MW682196) & Goat & Poland & $\begin{array}{l}\text { Rudzinska, } \\
\text { unpublished }\end{array}$ & 99.08 \\
\hline Buffalo10_4 & ST14 (MW682196) & Goat & Poland & $\begin{array}{l}\text { Rudzinska, } \\
\text { unpublished }\end{array}$ & 99.08 \\
\hline Buffalo10_5 & ST14 (MW682196) & Goat & Poland & $\begin{array}{l}\text { Rudzinska, } \\
\text { unpublished }\end{array}$ & 99.08 \\
\hline Buffalo7_2 & ST14 (MW682196) & Goat & Poland & $\begin{array}{l}\text { Rudzinska, } \\
\text { unpublished }\end{array}$ & 98.90 \\
\hline Buffalo7_3 & ST14 (MW682196) & Goat & Poland & $\begin{array}{l}\text { Rudzinska, } \\
\text { unpublished }\end{array}$ & 98.72 \\
\hline Buffalo6_10 & ST14 (MW682196) & Goat & Poland & $\begin{array}{l}\text { Rudzinska, } \\
\text { unpublished }\end{array}$ & 98.72 \\
\hline Buffalo10_3 & ST14 (MW682196) & Goat & Poland & $\begin{array}{l}\text { Rudzinska, } \\
\text { unpublished }\end{array}$ & 98.75 \\
\hline Buffalo1_5 & ST14 (MW682196) & Goat & Poland & $\begin{array}{l}\text { Rudzinska, } \\
\text { unpublished }\end{array}$ & 99.08 \\
\hline Buffalo6_6 & ST14 (MW682196) & Goat & Poland & $\begin{array}{l}\text { Rudzinska, } \\
\text { unpublished }\end{array}$ & 99.08 \\
\hline Pig40 & ST5 (MK801418) & Pig & Romania & $\begin{array}{c}\text { Wylezichet al., } \\
2019 \text { [29] }\end{array}$ & 100 \\
\hline Pig42 & ST5 (MN493729) & Wild boar & South Korea & $\begin{array}{l}\text { Lee and Kwak, } \\
\text { unpublished }\end{array}$ & 100 \\
\hline Pig43 & ST5 (MN493729) & Wild boar & South Korea & $\begin{array}{l}\text { Lee and Kwak, } \\
\text { unpublished }\end{array}$ & 100 \\
\hline Pig45 & ST5 (MN493729) & Wild boar & South Korea & $\begin{array}{l}\text { Lee and Kwak, } \\
\text { unpublished }\end{array}$ & 100 \\
\hline Pig46 & ST5 (MN493729) & Wild boar & South Korea & $\begin{array}{l}\text { Lee and Kwak, } \\
\text { unpublished }\end{array}$ & 100 \\
\hline Pig50 & ST5 (MN493729) & Wild boar & South Korea & $\begin{array}{c}\text { Lee and Kwak, } \\
\text { unpublished }\end{array}$ & 100 \\
\hline Goat51 & ST5 (MN493729) & Wild boar & South Korea & $\begin{array}{l}\text { Lee and Kwak, } \\
\text { unpublished }\end{array}$ & 100 \\
\hline Deer55 & ST5 (MK801418) & Pig & Romania & $\begin{array}{l}\text { Wylezichet al., } \\
2019 \text { [29] }\end{array}$ & 100 \\
\hline
\end{tabular}

Alleles named using the Blastocystis database (http://pubmlst.org/Blastocystis/, accessed on 1 February 2021) allowed the detection of three distinct alleles (i.e., allele 17, 115 , and 153) within the ST5 found here, from fallow deer, pig, and goat hosts, respectively. Allele 157 was observed in the isolates ST14 from the water buffaloes, while alleles 122, 41, and 152 were identified within the ST6, ST7, and ST10, isolated from chicken, pheasant, and sheep, respectively (Table 1). In addition, the isolates ST6 and ST7 detected in pheasant and chicken in the present study showed a high similarity (99-100\%, respectively) with the ST6 and ST7 sequences subtyped from the human host in Italy $[13,15]$. 


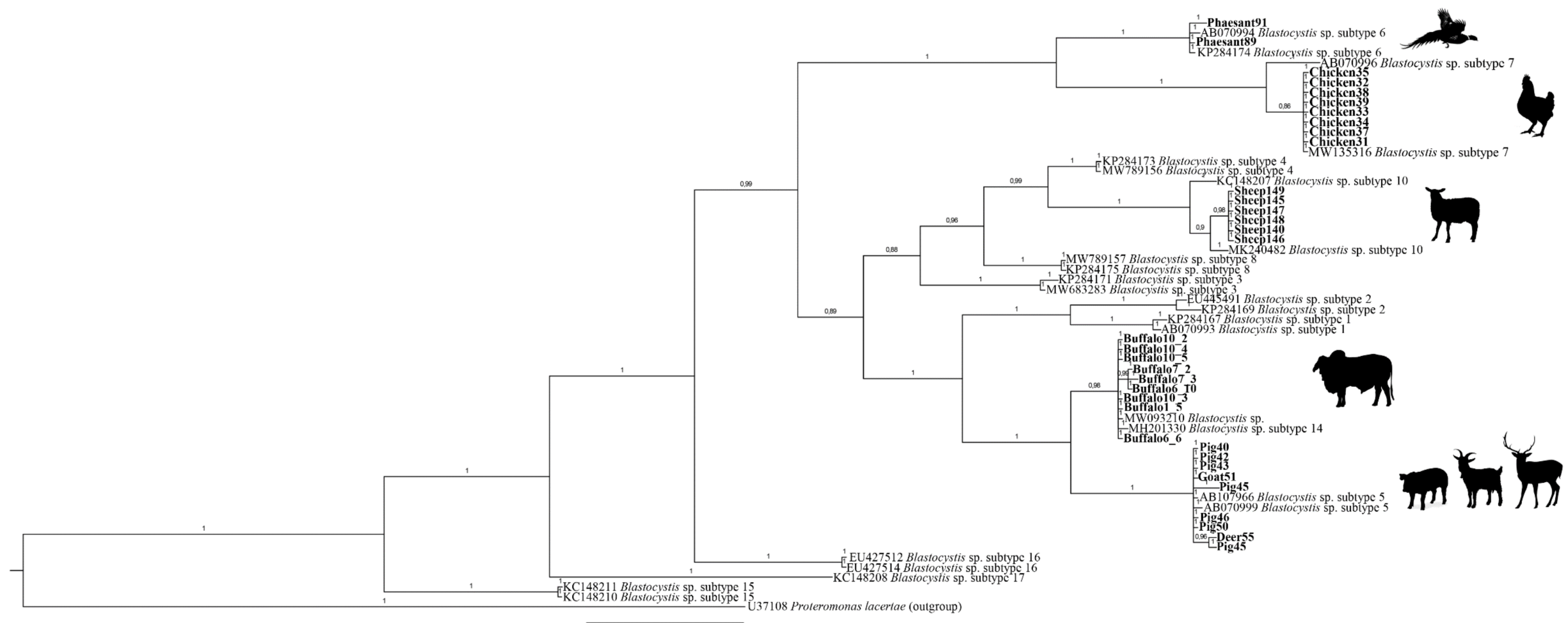

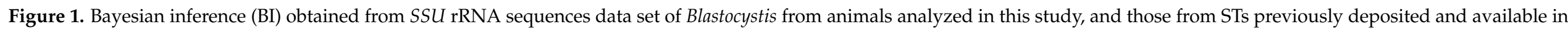

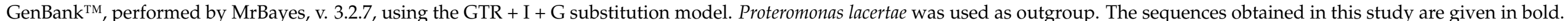
Taxon labels consist of GenBank number followed by subtype name. Icons indicate where the specimens were collected. 


\section{Discussion}

To the best of our knowledge, this study represents the widest survey on Blastocystis STs in farmed animals performed so far in Italy, including a total of 14 different animal species. The study evidences the occurrence of the protist in about $30 \%$ of the analyzed livestock, showing the circulation among them of five Blastocystis STs genetically identified, i.e., ST5, ST6, ST7, ST10, and ST14. These findings improve the current knowledge on the animal species harboring Blastocystis in Italy and support the role of these animal species as potential sources of human infections. Indeed, the comparison of sequences from animals to those from human isolates, such as ST6 and ST7, evidenced a high similarity $(99-100 \%)$ among animal and human isolates identified in this and our previous study, respectively [13-15]. Accordingly, allele analysis has shown the occurrence of the same alleles (i.e., 122 and 41) that have been found in ST6 and ST7, respectively, isolated from both humans $[13,15]$ and animals (present study), suggesting that poultry may be a source of human infection.

We cannot depict the precise mode of circulation between animals and humans of those STs; however, we could hypothesize that it may happen through contaminated water with animal stools [6]. Indeed, Blastocystis has been reported as a neglected waterborne protist and recently found in drinking water [18,30], a drinking water treatment plant [31], and ready-to-eat packaged salads [17]. However, the identification of zoonotic STs and alleles in edible animals such as poultry suggests the potential risk of Blastocystis transmission also by human handling of those farmed animals, as well as through the consumption of products of animal origin (e.g., eggs). Further investigation aimed to detect Blastocystis in different food matrices may contribute to clarifying the source of infection and patterns of transmission to humans of such zoonotic STs in Italy.

In recent years, several studies willing to address the issue of Blastocystis pathogenicity in humans suggested that it could be related to genetic differences of distinct STs [32,33], correlating with the ST1, ST4, and ST7 with pathological alterations in humans, while ST2 and ST3 have been identified as non-pathogenic [33-35]. A recent multi-locus sequence typing analysis of Blastocystis ST3 and ST4 has provided valuable insight into genetic variation within and between the two subtypes, evidencing a high or low level of genetic diversity at the intra-subtype level in ST3 and ST4, respectively [35]. Similar results were obtained in our previous survey from Italian patients [13] where three haplotypes (H1, H3, and H7) have been identified in ST3 isolates, while a single haplotype (H2) was observed in ST4 symptomatic patients. Thus, we suggested that intra-subtype diversity shown by ST3 and ST4 could be linked to the evolutionary history of Blastocystis subtypes, and that ST3 may have co-evolved with human hosts over a longer period than that experimented by ST4. This latter, instead, may more recently have had a spillover from rodents to humans; therefore, it shows a low level of genetic variability. According to the hypothesis of the recent evolutionary history of the ST4, a higher pathogenicity in humans was observed as due to ST4, with respect to other subtypes, found to be associated in patients with IBS, IBD, or chronic diarrhea [13].

In this study, similar consideration may be extended to the ST7, which has been reported to be strongly associated with gastrointestinal symptoms in humans and showed pathogenic properties, not observed in other STs, as well as an extensive intra- and intersubtype variability in citopathogenicity $[33,36]$. According to our experience, features of gastro-intestinal symptoms were also found in human patients harboring ST7, confirming its pathogenetic role (Mattiucci and Gabrielli, personal communication). Conversely, the identification of allele 41 observed in ST7 isolates from both humans and animals in Italy seems to suggest the existence of a low level of intra-subtype genetic variability, in contrast with that previous reported [33]. However, this anecdotic finding should be confirmed by genetic investigation carried out on several other samples corresponding to ST7 from both animals and humans. Furtherly, molecular epidemiology carried out simultaneously on fecal samples collected from humans and animals sharing farm enclosures and environ- 
mental characteristics will help to clarify the circulation of the same Blastocystis STs and alleles among those hosts.

Despite that the present study represents the widest Blastocystis survey performed thus far in farmed animals in Italy, some limitations related to the fact that few samples from some animal species (i.e., from fallow deer or from turkey) were collected should be taken into account. As a consequence, any conclusive consideration about the possible association between the occurrence of certain subtypes in some animal species or the lack of Blastocystis in some others cannot be definitively drawn. Further, as the epidemiological scenario described here was restricted to a few Italian regions, further surveys should be planned to include other animal species and more samples from the above tested animals, as well as from other geographical areas of Italy. In addition, because possible multiple co-infection by distinct STs would occur in the same farmed animal, an RT-PCR protocol would be developed based on the melting profiles in order to simultaneously identify different subtypes, or alternatively the cloning protocol, such as that proposed in other studies [8], would be adopted in future epidemiological studies. Another critical issue concerns the amplicons (26 out 60 ) that were positive with the primers proposed by Santín et al., 2011 [24] and with those described in Scicluna et al. [25], but they were not included in the phylogenetic analysis as we did not obtain readable products for the entire region (about $600 \mathrm{bp}$ ) analyzed with the BI. Despite that we cannot totally exclude that some of these amplicons could be the product of unspecific amplifications, all 26 amplicons were included in the total of positive samples as they were amplified with two protocols described for the identification of Blastocystis [24,25].

Moreover, the sampling was devoted to a particular group of animals, which were also selected for their possible role in the transmission of the protist also by derived food product such as eggs. Therefore, further parasitological and molecular investigations need to be carried out with the aim to evaluate other potential animal reservoirs of Blastocystis in Italy and to investigate the possible food-borne transmission of the protist.

\section{Conclusions}

The outcome of this study may be considered as a starting point to define the distribution of Blastocystis STs in different animal hosts in Italy and to hypothesize pathways of the zoonotic transmission of the protist.

Thus, it becomes evident that a greater knowledge of the evolutionary history of Blastocystis STs could, in future, explain any pathogenic aspects related to distinct subtypes. Studies on the genetic variation within and among identified subtypes may elucidate possible co-evolutionary aspects, and provide data for understanding Blastocystis biology, host-parasite interaction, and pathogenicity to humans.

Lastly, as Blastocystis has been reported as a neglected waterborne protist, further investigations are needed to identify other food matrices and vehicles as sources of transmission to human and animal hosts in Italy.

In conclusion, these findings represent only the tip of the iceberg concerning the epidemiology of Blastocystis in Italy and suggest the need to apply molecular analysis to demonstrate the transmission dynamics among humans, animals, and the environment of this so far debated plastic protist.

Author Contributions: Conceptualization, data curation, writing-original draft preparation, funding acquisition S.G. and S.M.; methodology, M.P., F.F. and R.A.A.; software, M.P.; validation; E.B., G.G., E.N., L.R. and R.A.A.; data curation, S.G.; writing-original draft preparation, S.G., M.P. and S.M.; writing-review and editing, visualization, S.G., M.P., F.F., E.B., G.G., E.N., L.R., R.A.A. and S.M.; supervision, S.G. and S.M.; project administration, S.M.; funding acquisition, S.G. and S.M. All authors have read and agreed to the published version of the manuscript.

Funding: This study was supported by Sapienza University of Rome, Progetti di Ricerca Università [Grant numbers: RM11615506189BE0, 2016; RM11715C81DDD2F3, 2017; RM11816432E08126, 2018] and by IILA, International Italian-Latin American Organization [Fellowship IILA-MAECI/DGCS assigned to R. Aco Alburqueque]. 
Institutional Review Board Statement: Not applicable.

Informed Consent Statement: Not applicable.

Conflicts of Interest: The authors declare no conflict of interest.

\section{References}

1. Adl, S.M.; Bass, D.; Lane, C.; Lukeš, J.; Schoch, C.L.; Smirnov, A.; Agatha, S.; Berney, C.; Brown, M.; Burki, F.; et al. Revisions to the classification, nomenclature, and diversity of eukaryotes. J. Eukaryot. Microbiol. 2019, 66, 4-119. [CrossRef]

2. Alfellani, M.A.; Stensvold, C.R.; Vidal-Lapiedra, A.; Onuoha, E.S.U.; Fagbenro-Beyioku, A.F.; Clark, C.G. Variable geographic distribution of Blastocystis subtypes and its potential implications. Acta Trop. 2013, 126, 11-18. [CrossRef]

3. Gabrielli, S.; Stensvold, C.R.; Mattiucci, S. Blastocystis. Reference Module in Biomedical Sciences; Elsevier: Amsterdam, The Netherlands, 2021.

4. Suresh, K.; Ng, G.C.; Ramachandran, N.P.; Ho, L.C.; Yap, E.H.; Singh, M. In vitro encystment and experimental infections of Blastocystis hominis. Parasitol. Res. 1993, 79, 456-460. [CrossRef] [PubMed]

5. Yoshikawa, H.; Yoshida, K.; Nakajima, A.; Yamanari, K.; Iwatani, S.; Kimata, I. Fecal-oral transmission of the cyst form of Blastocystis hominis in rats. Parasitol. Res. 2004, 94, 391-396. [CrossRef] [PubMed]

6. Tan, K.S.W. New Insights on classification, identification, and clinical relevance of Blastocystis spp. Clin. Microbiol. Rev. 2008, 21, 639-665. [CrossRef]

7. Stensvold, C.R.; Clark, C.G. Pre-empting pandora's box: Blastocystis subtypes revisited. Trends Parasitol. 2020, 36, $229-232$. [CrossRef] [PubMed]

8. Maloney, J.; Santin, M. Mind the gap: New full-length sequences of Blastocystis subtypes generated via oxford nanopore minion sequencing allow for comparisons between full-length and partial sequences of the small subunit of the ribosomal RNA gene. Microorganisms 2021, 9, 997. [CrossRef]

9. Alfellani, M.A.; Taner-Mulla, D.; Jacob, A.; Imeede, C.A.; Yoshikawa, H.; Stensvold, C.R.; Clark, C.G. Genetic diversity of Blastocystis in livestock and zoo animals. Protist 2013, 164, 497-509. [CrossRef] [PubMed]

10. Cian, A.; El Safadi, D.; Osman, M.; Moriniere, R.; Gantois, N.; Benamrouz-Vanneste, S.; Delgado-Viscogliosi, P.; Guyot, K.; Li, L.-L.; Monchy, S.; et al. Molecular epidemiology of Blastocystis sp. in various animal groups from two French zoos and evaluation of potential zoonotic risk. PLoS ONE 2017, 12, e0169659. [CrossRef]

11. Wawrzyniak, I.; Poirier, P.; Viscogliosi, E.; Dionigia, M.; Texier, C.; Delbac, F.; El Alaoui, H. Blastocystis, an unrecognized parasite: An overview of pathogenesis and diagnosis. Ther. Adv. Infect. Dis. 2013, 1, 167-178. [CrossRef]

12. Meloni, D.; Sanciu, G.; Poirier, P.; El Alaoui, H.; Chabé, M.; Delhaes, L.; Dei-Cas, E.; Delbac, F.; Fiori, P.L.; Di Cave, D.; et al. Molecular subtyping of Blastocystis sp. isolates from symptomatic patients in Italy. Parasitol. Res. 2011, 109, 613-619. [CrossRef] [PubMed]

13. Mattiucci, S.; Crisafi, B.; Gabrielli, S.; Paoletti, M.; Cancrini, G. Molecular epidemiology and genetic diversity of Blastocystis infection in humans in Italy. Epidemiol. Infect. 2015, 144, 635-646. [CrossRef]

14. Sulekova, L.F.; Gabrielli, S.; Furzi, F.; Milardi, G.L.; Biliotti, E.; De Angelis, M.; Iaiani, G.; Fimiani, C.; Maiorano, M.; Mattiucci, S.; et al. Molecular characterization of Blastocystis subtypes in HIV-positive patients and evaluation of risk factors for colonization. BMC Infect. Dis. 2019, 19, 876-877. [CrossRef]

15. Gabrielli, S.; Furzi, F.; Sulekova, L.F.; Taliani, G.; Mattiucci, S. Occurrence of Blastocystis-subtypes in patients from Italy revealed association of ST3 with a healthy gut microbiota. Parasite Epidemiol. Control 2020, 9, e00134. [CrossRef] [PubMed]

16. Piubelli, C.; Soleymanpoor, H.; Giorli, G.; Formenti, F.; Buonfrate, D.; Bisoffi, Z.; Perandin, F. Blastocystis prevalence and subtypes in autochthonous and immigrant patients in a referral centre for parasitic infections in Italy. PLoS ONE 2019, 14, e0210171. [CrossRef]

17. Caradonna, T.; Marangi, M.; Del Chierico, F.; Ferrari, N.; Reddel, S.; Bracaglia, G.; Normanno, G.; Putignani, L.; Giangaspero, A. Detection and prevalence of protozoan parasites in ready-to-eat packaged salads on sale in Italy. Food Microbiol. 2017, 67, 67-75. [CrossRef] [PubMed]

18. Angelici, M.C.; Nardis, C.; Scarpelli, R.; Ade, P. Blastocystis hominis transmission by non-potable water: A case report in Italy. N. Microbiol. 2018, 41, 173-177.

19. Masucci, L.; Graffeo, R.; Bani, S.; Bugli, F.; Boccia, S.; Nicolotti, N.; Fiori, B.; Fadda, G.; Spanu, T. Intestinal parasites isolated in a large teaching hospital, Italy, 1 May 2006 to 31 December 2008. Eurosurveillance 2011, 16, 19891. [CrossRef] [PubMed]

20. Capasso, M.; Maurelli, M.P.; Ianniello, D.; Alves, L.C.; Amadesi, A.; Laricchiuta, P.; Silvestre, P.; Campolo, M.; Cringoli, G.; Rinaldi, L. Use of Mini-FLOTAC and Fill-FLOTAC for rapidly diagnosing parasitic infections in zoo mammals. Rev. Bras. Parasitol. Veterinária 2019, 28, 168-171. [CrossRef] [PubMed]

21. Gazzonis, A.L.; Marangi, M.; Zanzani, S.A.; Villa, L.; Giangaspero, A.; Manfredi, M.T. Molecular epidemiology of blastocystis sp. in dogs housed in italian rescue shelters. Parasitol. Res. 2019, 118, 3011-3017. [CrossRef]

22. Zanzani, S.A.; Gazzonis, A.L.; Epis, S.; Manfredi, M.T. Study of the gastrointestinal parasitic fauna of captive non-human primates (Macaca fascicularis). Parasitol. Res. 2016, 115, 307-312. [CrossRef]

23. Russini, V.; Di Filippo, M.M.; Fanelli, R.; Polidori, M.; Berrilli, F.; Di Cave, D.; Novelletto, A.; Calderini, P. Characterization of prevalence and genetic subtypes of blastocystis sp. in wild and domestic Suidae of central Italy aided by amplicon NGS. VeterParasitol. Reg. Stud. Rep. 2020, 22, 100472. [CrossRef] 
24. Santín, M.; Gomez_Munoz, M.T.; Solano-Aguilar, G.; Fayer, R. Development of a new PCR protocol to detect and subtype blastocystis spp. from humans and animals. Parasitol. Res. 2011, 109, 205-212. [CrossRef] [PubMed]

25. Scicluna, S.M.; Tawari, B.; Clark, C.G. DNA barcoding of blastocystis. Protist 2006, 157, 77-85. [CrossRef] [PubMed]

26. Stensvold, C.R.; Suresh, G.K.; Tan, K.S.; Thompson, R.A.; Traub, R.; Viscogliosi, E.; Yoshikawa, H.; Clark, C.G. Terminology for blastocystis subtypes-A consensus. Trends Parasitol. 2007, 23, 93-96. [CrossRef]

27. Ronquist, F.; Huelsenbeck, J.P. MrBayes 3: Bayesian phylogenetic inference under mixed models. Bioinformatics 2003, 19, 1572-1574. [CrossRef] [PubMed]

28. Kimura, M. A simple method for estimating evolutionary rates of base substitutions through comparative studies of nucleotide sequences. J. Mol. Evol. 1980, 16, 111-120. [CrossRef]

29. Wylezich, C.; Belka, A.; Hanke, D.; Beer, M.; Blome, S.; Hoeper, D. Metagenomics for broad and improved parasite detection: A proof-of-concept study using swine faecal samples. Int. J. Parasitol. 2019, 49, 769-777. [CrossRef]

30. Eroglu, F.; Koltas, I.S. Evaluation of the transmission mode of B. hominis by using PCR method. Parasitol. Res. 2010, 107, 841-845. [CrossRef]

31. Richard, R.L.; Ithoi, I.; Majid, M.A.A.; Sulaiman, W.Y.W.; Tan, T.C.; Nissapatorn, V.; Lim, Y.A.L. Monitoring of Waterborne Parasites in Two Drinking Water Treatment Plants: A Study in Sarawak, Malaysia. Int. J. Environ. Res. Public Health 2016, 13, 641. [CrossRef]

32. Stensvold, C.R.; Lewis, H.C.; Hammerum, A.M.; Porsbo, L.J.; Nielsen, S.S.; Olsen, K.E.P.; Arendrup, M.C.; Nielsen, H.V.; Mølbak, K. Blastocystis: Unravelling potential risk factors and clinical significance of a common but neglected parasite. Epidemiol. Infect. 2009, 137, 1655-1663. [CrossRef] [PubMed]

33. Wu, Z.; Mirza, H.; Tan, K.S.W. Intra-subtype variation in enteroadhesion accounts for differences in epithelial barrier disruption and is associated with metronidazole resistance in blastocystis subtype-7. PLoS Negl. Trop. Dis. 2014, 8, e2885. [CrossRef] [PubMed]

34. Domínguez-Márquez, M.V.; Guna, R.; Munoz, C.; Gómez-Muñoz, M.T.; Borras, R. High prevalence of subtype 4 among isolates of blastocystis hominis from symptomatic patients of a health district of Valencia (Spain). Parasitol. Res. 2009, 105, 949-955. [CrossRef]

35. Stensvold, C.R.; Alfellani, M.; Clark, C.G. Levels of genetic diversity vary dramatically between blastocystis subtypes. Infect. Genet. Evol. 2012, 12, 263-273. [CrossRef]

36. Nieves-Ramírez, M.E.; Partida-Rodríguez, O.; Laforest-Lapointe, I.; Reynolds, L.A.; Brown, E.M.; Valdez-Salazar, A.; Morán-Silva, P.; Rojas-Velázquez, L.; Morien, E.; Parfrey, L.W.; et al. Asymptomatic intestinal colonization with protist blastocystis is strongly associated with distinct microbiome ecological patterns. mSystems 2018, 3, e00007-18. [CrossRef] [PubMed] 